\title{
Requirement Management Strategy
}

\author{
Dagný Hauksdóttir and Poul E. Nielsen
}

\begin{abstract}
For every organization it holds true that resources are limited. It is therefore critical for success to direct the available resources in the right directions. For this purpose it might be valuable identifying the key business processes and creating strategic plans for their future objectives. Such strategic plans would be more closely aligned with daily operational management and also enable operational improvement opportunities to surface to a strategic level. This paper focuses on the field of Requirement Management (RM). RM is considered a key business process for directing attention to creating customers value and to ensure a successful project startup. The objective of the paper is to establish an understanding of the purpose of having a RM strategy and what the content of a requirement strategy should be. A case study presenting a strategy to RM generated at Danfoss Power Electronics is presented. The results found were that defining a RM strategy proved to provide several benefits e.g. aligning and directing resources across business segments, enabling identification and assignment of roles related to requirement operations across functional areas and establishing a long term plan for how to achieve the identified future objectives.
\end{abstract}

Index Terms-Requirement management, operation-based strategy, strategic management.

\section{INTRODUCTION}

Capabilities are a company's proficiency in combining people, process and technology which allow it to continually distinguish itself along the dimensions that are important to its customers [1]. Those that can consistently create new, more effective ways of delivering value to customers will stay ahead of the pack [2]. Selecting the right R\&D strategy and better execution of the product life cycle management processes to speed up development is critical for being competitive [3]. Resources are limited and organizations must therefore ensure that they are directed towards the right objectives. They must align and agree on a high level what is the right direction as otherwise resources will be wasted in doing the wrong things. To address this problem companies make strategies to curve the directions of where the company is going. The key to a successful strategy implementation is often based on operations advantages. To ensure compliance of operational processes to a business strategy an operation-based strategy can be created. Superior operations effectiveness improves the company's competitiveness and is difficult to imitate [2].

Requirement Management (RM) presents concepts of

Manuscript received April 1 2014; revised May 27, 2014. This work was supported in part by Danfoss PE, Denmark.

Dagný Hauksdóttir is with the Engineering Design and Product Development, Technical University of Denmark (e-mail: dagha@dtu.dk).

Poul E. Nielsen is with Danfoss' Power Electronics Division in Graasten, Denmark (e-mail: Poul_Erik_Nielsen@danfoss.com). identifying, collecting, and allocating functions and quality parameters that an intended system must meet to satisfy its customers' needs. In the development of complex systems, $\mathrm{RM}$ is becoming a more important and a more complex activity. Effective RM can secure correct understanding of the customer needs leading to a system that better satisfies their expectations, as well as an effective project startup. RM can however consume a considerable amount of resources in the product development process. For a large organization with many product lines, business units and technological expertise the requirement activities might become scattered and incoherent, increasing the complexity of the RM operations. Inadequate RM is generally considered as one of the major causes for product failures in product development projects [4], [5].

However little has been written about defining RM on an operation-based strategic level. Strategic ways to deal with specific issues in RM have been suggested [6], [7]. They however, only include the part of RM approach that are a part of the strategic solution and therefore leave out other attributes that must be specified for a complete requirements approach. What these contributions miss is the realization of a generic companywide RM strategy, clearly describing the directions for RM.

In this paper an operation-based strategy for RM is suggested. The strategic plan should cover all elements of RM on a high level and be supported by management. In this paper a suggestion for the key content of a RM strategy is described and a case study from Danfoss Power Electronics (PE) is presented.

\section{STRATEGIC MANAGEMENT}

Strategic planning is defined as plans that are organization-wide, establish overall objectives, and position an organization in terms of its environment [8]. Traditionally, formal strategic planning is conducted by establishing a vision and objectives and then a high level course of action to achieve these objectives [1]. Strategic management provides overall direction to the enterprise. It entails specifying the organization's objectives, developing policies and plans designed to achieve these objectives, and then allocating resources to implement the plans.

Strategy is an attempt to get the desirable ends with the available means [9] and ensure that members of the organization are working toward the same goals. Strategy is important because the resources available to achieve these goals are limited. Within an organization, many operational goals are pursued simultaneously, leading to the concurrent and overlapping execution of potentially large numbers of processes. Although the goals are in some sense 
complementary, the limited resource availability causes competition between processes. One process might consume more than its allocated share of resources, leading to delays in others. Often, unrealistic expectations coupled with limited resources renders the achievement of every goal on time impossible; in such situations, precedence is given to those goals thought most important to the organization, pulling resources from other processes without regard to the long-term consequences [10]. This is why strategic focus is important; to ensure that the organization does not sacrifices long term objectives for short term winnings.

The problems in strategic management seem to lie in implementation rather than formulation. Authors of strategic business plans usually look outward; their focus is on the external environment in which the business operates. Implementation is about understanding strategic objectives and ensuring that an organization's operations, human and technological resources are contributing to the delivery of the strategy. Executing the strategy more effectively than its competitors can by itself create valuable competitive advantages for the company [2]. The problem is the mismatch or decoupling between the strategic plans generated by high management and the day-to-day operations of the company.

A business process is, usually, understood as a sequence of activities, functions or tasks which leads to a well-defined operational goal [5]. Operational planning is defined as plans that specify details on how overall objectives are to be achieved [4]. Operational plans are highly tactical plans that enable taking action toward implementing specific activities.

Specialists who draw up operational plans focus on the dimensions of their own internal world: parts, lists, drawing work standards, schedules, plant layout etc. When the business strategy is changed, the authors of the operating plans need to couple functional procedures. Effectively adapting to a new set of competitive priorities requires more than simply making a single change in its operating systems. A whole series of interlocked alterations is required, and this takes time as well as money. This may require hundreds of specialists to be retrained and new work procedures to be documented [11].

Most operational plans are focused on short-term objectives, however to achieve true process improvements it might be necessary to also make long term plans for a business process. Strategic management can also be applied to operational business processes. In this context strategy management is defined as the business process by which a business develops, deploys, implements, monitors, reviews and re-develops its operations strategy [12].

For truly implementing strategic changes effective strategies tend to emerge from a series of 'strategic subsystems', each of which attacks a specific class of strategic issues, but which are blended incrementally and opportunistically to generate a company's business strategy [1]. Competence-based strategy deals with establishing excellence in the core competencies necessary to operate effectively in its chosen marketplace in the future. Such critical competencies include things such as managing brands, product launching, manufacturing and operational excellence. Operations-based advantage draws its power from the fact that companies succeed in the long run by being able to do certain things better than their competitors can [2]. It is these competency-based strengths that enable a company to react, adapt and prosper in a competitive environment. Competency-based strategies should have a clarity which gives greater direction to implementation [1].

Superior operations effectiveness not only serves to strengthen a company's existing competitive position, but, when based on capabilities that are embedded in the company's people and operating processes, is inherently difficult to imitate. They often demand substantial organizational change and sometimes even a complete realignment of management philosophy and corporate culture. The fact that operations effectiveness is difficult to imitate or transfer is what makes it so valuable. For this reason it can provide the basis for a sustainable competitive advantage. Moreover, this sort of competitive advantage tends to be less visible to competitors which may not perceive the potential, or even its existence, until it's too late, at which time the employed approaches are no longer easily replicable [2]. As $\mathrm{RM}$ is a key business process to identify and provide value to customers, operations-based advantage in the business process could provide the organization with unique strategic competences to exceed in the market place.

\section{WHAT IS A RM STRATEGY?}

A requirement strategy is a high level strategic plan for the operational process of RM. It includes a strategy for the direction, objectives and long term plan for the operational process. The difference between the requirement strategy and the operational management of the requirement process are the following:

Level of detail: The requirement strategy includes high level goals for the requirement process and plans for how to achieve those goals. More detailed process plans will be worked out by the requirement process management.

Scope: The strategy should strive to accomplish synergy for the RM across the organization; this includes, Business Segments (BS), technological domains, projects, etc. The detailed process implementation might differentiate between organizational units.

Management approval: The RM strategy is created and approved, by a higher level management than is involved in day-to-day RM operations. This is not necessary the highest level of management in the organization, but a management level that has the authority to commit to assigning the necessary resources and roles to implement strategy.

Involvement of stakeholders: An owner must be appointed to take on the responsibility of creating a RM strategy. A broad range of key stakeholders to the RM process should be identified to provide their input and feedback. A formal team might also be created to support the strategy owner in creating the strategy.

Time period: It takes the organization a considerable time and effort to implement the requirement strategy in its daily operations. Long term commitment is important to harvest benefits from the requirement strategy 


\section{RM STRATEGY}

The content elements of a RM strategy are in many ways similar to a traditional business strategy. However, the scope of the operations-based strategy is inward viewed the RM process as a defined organizational element.

\section{A. Identifying the Objectives with Creating the Strategy}

First the objectives and purpose of creating the RM strategy and how it will be used must be identified. As described above there are some generic objectives for making a RM strategy, such as: to direct resources in the requirement process and to align high level process elements across the organization. However, the organization will likely have more specific modifications for creating a RM strategy. It is important that the organization identifies the more specific objectives for their case and relates them to some more specific objects identified for the RM operation, e.g. to address specific issues, such as requirement traceability, requirement quality improvement, better capturing of customer needs, increased process efficiency, ensuring fulfilment of requirements etc. Understanding the objectives and their long term benefits will help to get resources assigned for the strategy implementation.

\section{B. Analyzing the Current Situation}

An important step of creating a strategy is to generate an understanding of the current situation. Here the requirement operation process is viewed as an organizational element by itself. It is important to evaluate both the internal status and activities of the RM operations as well as the external factors affecting the process. Those might as an example be events and activities in the organization outside the process, new external standards or changed focus from tools vendors. Involvement of all the most knowledgeable stakeholders in the organization is especially important in this activity both to collect the relevant information and to achieve a shared understanding of the current situation.

The SWOT analysis tool is commonly incorporated into the planning process to help develop strategies around organizational strengths and weaknesses, as well as the opportunities and threats that exist in the external environment. It is possible to conduct a SWOT analysis when generating a requirement strategy, similarly as for the traditional strategic planning. However, some other known tools, e.g. including competitors, will not be applicable.

After analyzing the current situation some further objectives might be identified, due to surfacing of new opportunities, priorities or weaknesses.

\section{Setting Directions for the Future}

In this part of the strategy the objective is to define the future directions and goals for the RM business process. These goals set a clear direction and they should ensure alignment between business units and development projects. These goals shall if possible be applicable and generic for the organization.

No existing identification on what a requirement strategy should contain is available. It is suggested that the RM strategy should touch upon the elements typically included in a RM approach. This is a fundamental difference than defining a strategy to deal with a specific issue of RM as previous contributions have presented [6], [7].

The major elements of RM are suggested:

- How will requirements be identified and evaluated?

- Which documents will be created?

- How will requirements be structured and classified?

- What will be the content of a requirement?

- How will the high level process description be?

- How will quality of requirements be ensured?

- How will the requirement sets/specification be organized?

- What traceability between requirements and other design elements will be established?

- How will reusability be established to support platform based product development?

Traditional strategic tools for setting the future goals for an organization, e.g. for product positioning, are not applicable the RM process and no official tools have been identified for the establishment of these elements.

\section{Roles and Responsibilities}

The necessary roles and positions related to the RM operation must be defined in the strategy. This is important because these roles likely exist across organizational units. The establishment of these roles and the allocation of resources is therefore out of the authority of the RM operation.

The description of roles should involve the skills and knowledge required to fill the role as well as the responsibility and authority. These must be carefully aligned.

Requirements are usually primarily worked on during product development projects. The commitment and allocation of resources in product development projects to work with requirements is therefore critical, especially as time and resource management is of essence in development projects. The commitment of the project office to allocate resources to accomplish the goals described in the strategy is necessary for its implantation.

\section{E. Planning How to Get There}

By measuring the analysis of the current situation compared to the future directions, major gaps in the current process can be identified. Plans for how to close these gaps and establish the defined future process will need to be identified.

Here some of the same project planning techniques as for planning development of new products and technologies in traditional strategic planning can be used. Tools such as technology maps, one-year plan and star model can be applied with some adjustments. Instead of planning product development, the implementation of processes and generation of asset is planned.

\section{F. Getting the Requirement Strategy Approved}

The requirement strategy must be reviewed and agreed by the key stakeholders. It must then be approved by all managers who will need to allocate resources to the RM operations. This will ensure that when schedules become tight, a commitment is undertaken to address the necessary 
activities to ensure compliance with the RM strategic objectives.

\section{CASE STUdY}

Danfoss Power Electronics (PE) is a Danish company with more than 3000 employees worldwide. The company manufactures a wide range of electrical and electronic products. RM practices have been used at the company for number of years and the company views RM as a key business process for achieving operational excellence in product development. The company uses a requirement tool and focuses highly on requirement reuse. The company has an objective of improving the quality of the requirements and increasing the efficiency and ease of creating requirement specifications.

The company has also incorporated product platform based development. To company considers reuse of requirements as a key ignition point for optimal design reuse. To accomplish this goal it is necessary to establish alignment between functional process units.

Several process improvement initiatives have been undertaken in RM in the recent past. These process improvements must be aligned to ensure that new processes are synergized across the organization. It must be ensured that all BSs and product development projects are committed to working in an aligned way and that the resources are directed towards common results. Sustainable requirements reuse furthermore requires commitment outside the RM office.

\section{A. Objectives with Strategy}

The following objectives were identified for the requirement strategy:

- To describe ownership, high level processes and roles \& responsibilities needed to establish and maintain Customer Requirement Specifications (CRS) and Product Requirement Specifications (PRS) in PE and to enable efficient re-use of requirements and to comply with the TS16949 standard.

- To secure that the requirements cover the whole product lifecycle and all technologies involved during the product development.

- To secure that the processes and the supporting IT tools can be tailored to fulfil the needs within each Business Segment.

- To secure that guidelines and templates are provided allowing for uniform use of the processes within PE.

- To secure that fulfilment of requirements can be tested efficiently during project execution.

- To secure that relations between requirements can be traced.

\section{B. Analysis of Current Situation}

A SWOT analysis was used to analyze the current situation of RM at the organization. Table 1 demonstrates some of the strength, weaknesses, opportunities and threats identified.

The SWOT analysis will be important when compared against the future objectives to identify the tasks needed to complete the implementation of the strategy.

TABLE I: A SWOT ANALYSIS OF THE CURRENT SITUATION IN RM

\begin{tabular}{|l|l|}
\hline Strengths & Weaknesses \\
\hline $\begin{array}{l}\text { Common database tool in nearly all } \\
\text { BS supporting version control }\end{array}$ & $\begin{array}{l}\text { Process and ownership for } \\
\text { managing reusable requirements } \\
\text { needs to be strengthened. }\end{array}$ \\
\hline $\begin{array}{l}\text { Requirements representing high } \\
\text { value domain knowledge for } \\
\text { different BAs }\end{array}$ & $\begin{array}{l}\text { Coherence between CRS and PRS } \\
\text { Specifications for not established } \\
\text { for all requirements }\end{array}$ \\
\hline $\begin{array}{l}\text { Created requirement structure } \\
\text { covering the whole life-cycle } \\
\text { supported by requirement template }\end{array}$ & $\begin{array}{l}\text { Requirements not always } \\
\text { documented in a reusable way; } \\
\text { generic and specific text is mixed } \\
\text { up. }\end{array}$ \\
\hline $\begin{array}{l}\text { Ownership and process for } \\
\text { consolidating company } \\
\text { requirements within some BSs. }\end{array}$ & $\begin{array}{l}\text { Insufficient governance to secure } \\
\text { re-use of requirements (+ solutions) }\end{array}$ \\
\hline $\begin{array}{l}\text { Training material and templates } \\
\text { available for writing requirements } \\
\text { and for using the database tool }\end{array}$ & Threats \\
\hline Opportunities & $\begin{array}{l}\text { If BS are not sufficiently aligned it } \\
\text { may hinder harvesting synergies } \\
\text { from re-using requirements. }\end{array}$ \\
\hline $\begin{array}{l}\text { Continue developing common } \\
\text { software feature model for products } \\
\text { families to improve re-use efficiency }\end{array}$ & $\begin{array}{l}\text { Database tool cannot handle the } \\
\text { complexity and may be close to get } \\
\text { out-phased by supplier }\end{array}$ \\
\hline $\begin{array}{l}\text { Use upcoming platform based } \\
\text { product projects to improve PRS } \\
\text { quality and to ensure coherence with } \\
\text { CRS }\end{array}$ & \\
\hline
\end{tabular}

\section{Setting Directions for the Future}

Next the outlines for the future of the RM process are specified.

\section{1) How will requirements be established}

Requirements in a product development project will be established with two main approaches:

- The PDP Lean Voice of the Customer (LVoC) approach where focus is on cooperating directly with stakeholder and customer to discover their true needs.

- By reusing requirements. After discovering the customer needs and analyzing the operational environment of the intended product, the reusable requirements asset will support the project team in defining a complete requirement specification.

\section{2) What documents will be created}

The requirements are collected in two specification documents provided by the project team. The definitions of the documents are as follows:

\section{Customer Requirement Specification - CRS:}

- Defines the general functions and properties which the product must have to fulfill requirements from customers, business stakeholders and authorities

- The project's core team and relevant specialists reviews the CRS

- The head of business segment, the business segment product manager and the project manager approve the CRS

\section{Product Requirements Specification - PRS:}

- Provides needed details to ensure that requirements can be implemented and tested

- It is consequently a more detailed and specific breakdown of the CRS 
- Designers and specialist from related technology areas review the PRS.

- The project manager approves the PRS

Possible changes after approval are managed through change requests.

\section{3) How will we structure and classify requirements}

The most important classification of the requirements is the definition of CRS and PRS requirements described above. All requirements must be classified as either CRS or PRS requirements. All PRS requirements must originate from a CRS requirement, meaning that they can be tracked back to a stakeholder need. How this traceability is established will however be the task of the operational management.

It is decided that a uniform and hierarchical way of structuring the CRS and the PRS must be followed in order to make it easier to harvest synergy across Danfoss PE's business Segments. The structure that will be followed for the CRS has 5 generic requirement types:

- Business requirements

- Standard and Law Requirements

- Product Properties

- Life phase requirements

- Architecture design requirements

A 2nd layer (Domain Layer) should be stable for each BS or Business Unit, although minor differences will be found between the BS/Business Units to include the specific scope of the different products. The structure shall support users in identifying requirements for the whole product lifecycle, which is one of the objectives of the strategy. Further details regarding classification of requirements, which exist on operational level, are left out of the strategy. It is up to the operational management how to implement those in detail.

\section{4) What will be the content of a requirement}

A standard template for requirements will make them more consistent and ensure that all the needed information is defined in a clear way. The Requirement template consists of three mandatory fields:

- Description: The description is intent of the requirement, stating in a clear way, what is required.

- Rationale: The rationale describes the reason behind the requirement's existence. It tells why the requirement is important and what contribution it makes to the product's purpose.

- Fit Criterion: The Fit criterion identifies quantified goals that the solution has to meet, they are acceptance criteria. The Fit Criterion must be written in a precise quantified manner so that solutions can be tested or evaluated.

And one optional field:

- Additional Information: Notes, Appendixes and other supporting material that contribute to the intention or understanding of the requirement.

Instructions for how to write each part of the requirement template will be provided in scheduled trainings, guideline documents and help support in the requirement tool. Establishing a Fit Criterion to the requirements is an important step for ensuring that they can be tested efficiently.

\section{5) High level process description}

Main high level process descriptions are outlined on one hand from the perspective of process steps and responsible roles (see Fig. 1) and on the other hand from the perspective of the reusable set and product requirement set knowledge management (see Fig. 2).

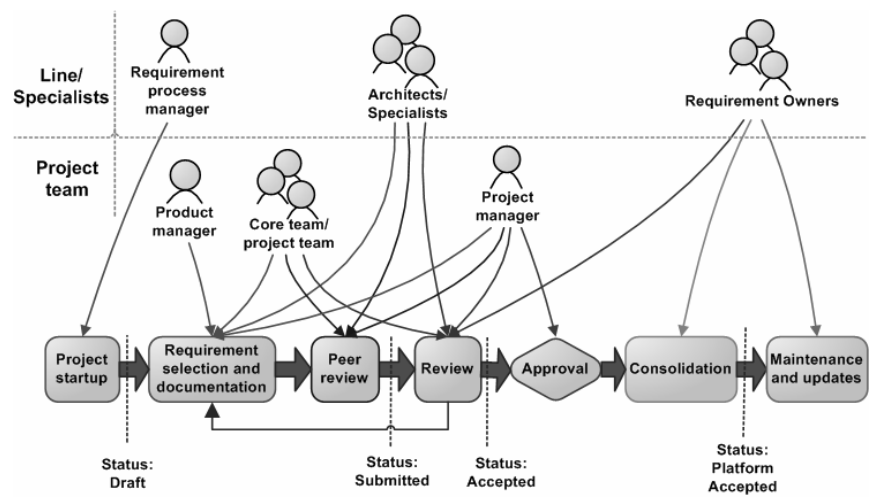

Fig. 1. High level process description including main process steps and roles.

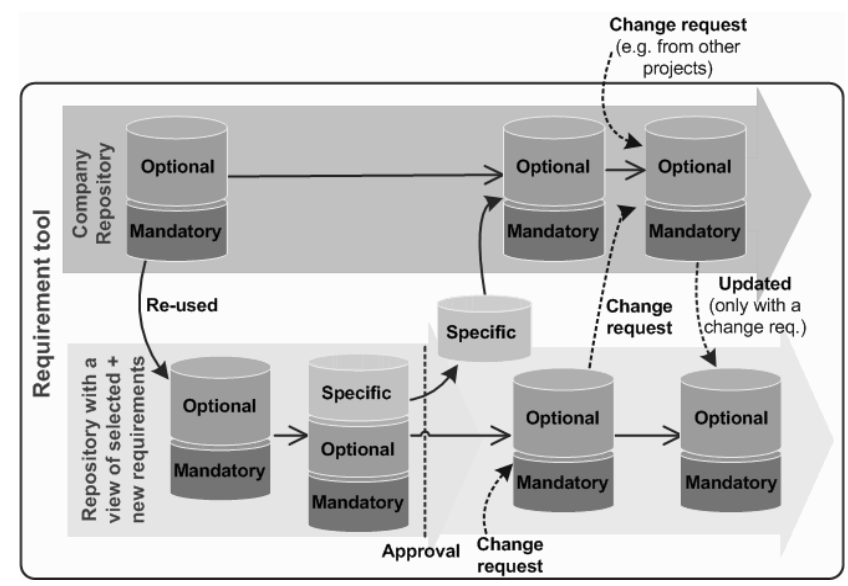

Fig. 2. High level process descriptions showing evolvement of requirement information.

These process descriptions highlight; the importance of supporting reuse as well as enabling creation of new and changed requirements, the need for ensuring that changes done by the project team are aligned with the reusable asset and the need for roles and responsibilities for managing the reusable asset.

The process communicates that all projects should re-use requirements if possible and that the additional process steps of consolidation and maintenance must be facilitated. The detailed implementation of these processes and the corresponding tools support is designed in more detail at the RM office and might differ between technical domains depending e.g. on the maturity of the requirement asset and the tool support. However, by describing the high level process synergy across the organization has been established.

6) Re-usable requirements establishment

To established re-usable RM some fundamental rules for the management of the reusable asset must be established. These rules primarily address how the reusable sets will be organized. The main rules identified for Danfoss PE are the following;

- Requirements which are expected to be re-used are collected in re-useable repositories in the PE database tool. The reusable asset must cover all technology areas. 
- Each business unit must appoint owners holding the responsibility to keep domain re-useable requirements updated (and cleaned up). BSs can decide to manage this ownership on a higher Business Unit level.

- The re-useable requirements must cover both CRS and PRS structured as shown above for new product development.

- The re-useable requirement repositories will be maintained based on a product view, allowing filtering out a CRS and a PRS for each product series.

- The coherence between the CRS and the PRS must be established where missing and kept over time to secure that the necessary knowledge of the real customer requirements do not erode when "Building Blocks" are re-used.

- Well structured requirement repositories shall enable cross BSs re-use.

- Global R\&D holds the responsibility to identify, build up and maintain common PE re-useable requirements (e.g. legal requirements).

Fig. 3 shows the build op of reusable repositories as well as the fundamental process rules.

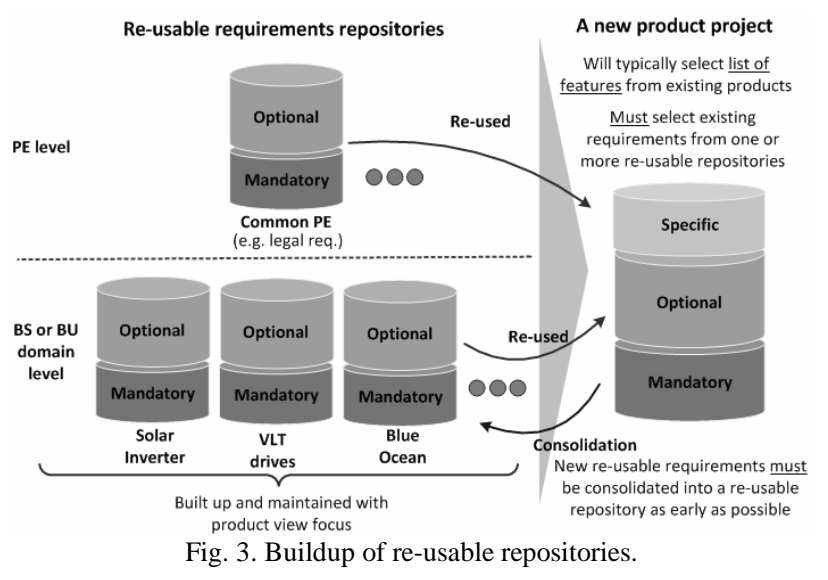

\section{7) Traceability between requirements and other design} elements

Other issues that are outlined in the strategy, is the establishment of traceability between the requirements and other design elements such as design specifications and test specification. The corresponding IT-tool chain is furthermore illustrated. To achieve this cooperation is required across the functional process units in the product development life cycle.

\section{Roles and Responsibilities}

The high level process description highlights that a sustainable management of requirements reuse will not be accomplished without creating new roles across the organization for maintaining the reusable asset and for ensuring anchoring in the global organization. Prior to the strategy creation the role of a requirement process manager had existed for a number of years. The roles defined in the strategy are shown in Table II:

An estimation of the owner effort is provided. It is however difficult to evaluate the exact effort as it depends strongly on; the volatility the specific requirements domain, the scope and size of new projects, the number of on-going projects, the number of products to be maintained separately and the quality and re-usability of existing requirements. The identification of owners addresses the first objective of generating the strategy.

TABLE II: IDENTIFIED ROLES AND RESPONSIBILITIES.

\begin{tabular}{|c|c|}
\hline Position & Roles \& Responsibilities \\
\hline \multicolumn{2}{|l|}{ Process Responsibility } \\
\hline $\begin{array}{l}\text { PE RM owner. } \\
\text { - Co-owners are appointed to } \\
\text { ensure anchoring in the global } \\
\text { organization }\end{array}$ & $\begin{array}{l}\text { - Ensure that the process is followed } \\
\text { across functions (compliance) } \\
\text { - Ensure alignment of the process } \\
\text { globally as needed. } \\
\text { - Approve the process and major } \\
\text { process changes upon } \\
\text { recommendation from the Process } \\
\text { Manager } \\
\text { - Approve requirement } \\
\text { improvement plan set up by the } \\
\text { Process Manager }\end{array}$ \\
\hline $\begin{array}{l}\text { PE Requirement Process Manager } \\
\text { - Co-managers are appointed to } \\
\text { support the global organization }\end{array}$ & $\begin{array}{l}\text { - Conduct training, secure global } \\
\text { deployment and continuously } \\
\text { improve the RM processes. } \\
\text { - Support projects to establish / use } \\
\text { the right structure in the IT tools } \\
\text { - Set up plan for requirement } \\
\text { improvements }\end{array}$ \\
\hline \multicolumn{2}{|l|}{ Assets Responsibility } \\
\hline $\begin{array}{l}\text { PE owners of Common PE level } \\
\text { Requirements } \\
\text { - An owner is appointed for each } \\
\text { Technology Area hosting } \\
\text { Common PE level Requirements }\end{array}$ & $\begin{array}{l}\text { - Ensure that the content is kept } \\
\text { updated (consolidated) to secure } \\
\text { that projects re-uses high quality } \\
\text { requirements } \\
\text { Push for re-use of existing } \\
\text { requirements whenever possible }\end{array}$ \\
\hline $\begin{array}{l}\text { BS or BU owners of Domain } \\
\text { Requirements } \\
\text { - CRS: Product Management / } \\
\text { Application Management holds } \\
\text { responsibility } \\
\text { - PRS: Technology Managers hold } \\
\text { responsibility }\end{array}$ & $\begin{array}{l}\text { - Ensure that the content is kept } \\
\text { updated (consolidated) to secure } \\
\text { that projects re-uses high quality } \\
\text { requirements } \\
\text { - Push for re-use of existing } \\
\text { requirements whenever possible }\end{array}$ \\
\hline
\end{tabular}

The skills of working with requirements are furthermore addressed as they are important to ensure a sufficient quality of requirements. It is suggested that the organization moves to a "Six Sigma" like approach for requirements skills, defined as:

- "Yellow belt": Basic level for development engineers and project managers

- "Green belt": Product managers, core team members and specialist writing and reviewing requirements

- "Black belt": Specialist and managers pro-actively looking at quality of requirements

\section{E. How to Get There}

Finally a plan is made for how to achieve the results specified in the RM strategy. First main tasks are identified and categorized depending on the required effort for completing them. These are identified as Step I, II and III gains.

Next the planned activities are scheduled on a indicative timeline, spanning 2.5 years. The timeline shows the evaluated start and finish point, duration and milestones of each of the most important tasks. The requirement process manager is then responsible for making more detailed plans 
for how to accomplish each task.

\section{F. Approval of the Requirement Strategy}

The requirement strategy is approved by the Global R\&D Management team. This is critical to ensure that the identified roles are established and to ensure commitment to the tasks completion and time plan for how to achieve the end results. The requirement process manger will create more detailed task descriptions for their responsibilities.

\section{DISCUSSION}

It is important not to underestimate the time and resources it takes to establish implement operational changes. It takes considerable experience for users to become good at RM and creating a quality asset of requirements can take years. The possession of such an asset is valuable to secure qualified and efficient platform based product development.

Because the RM takes place across functional and departmental boundaries it is important to have a spokesman that has the power and control of resources as well as the personal characteristics to drive the changes. The implementation of the RM strategy is mostly driven by work in product development projects that are usually working on tight deadlines. There can therefore be conflicting interests of getting things done on time or working according to the RM strategy. When resources come limited and deadlines come tight, the company must be committed to following certain procedure that has been agreed upon for the long term benefit of the organization.

There is a fundamental difference in the role of the RM strategy and the operation management. The role of the operation management is to carry out more detailed directions for how to realize the requirement strategy. Further details that are not described in the requirement strategy are described in the operation plan. This can e.g. be tool specific details, details related to business units and technologies of different nature or maturity etc. It is certain that the requirement strategy is more concrete and more directly affecting the daily operations, than a business strategy, well at the same time it can contributes to the higher level objectives of the company (e.g. platform based development and effective project startup).

Before documenting the requirement strategy, some of its topics were already in scope and on the agenda. However, by putting it down on paper and making a plan, the "talking about it" finished and the action could start. Just as for an efficient development project startup, it is important to affectively launch operational activities.

\section{CONCLUSION}

In this paper an outline generating a requirement strategy has been provided. The RM strategy has proved valuable for giving a direction in RM that aligns different efforts on product level, ensures that key stakeholders agree on the basic concepts and enable communicating those concepts clearly to the rest of the organization, to direct resources to the right activities and back up RM activities by high level management approval.

More guidance and experience regarding how to step-by-step brake corporate business strategies down the organizational latter, to operational plans and how to mitigate and align the operational strategies to achieve competitive performance would be a valuable course for future research.

\section{REFERENCES}

[1] C. Edwards, "Forging a Link between business Strategy and Business Reengineering," European Management Journal, vol. 12, no. 5, pp. 407-416, December 1994.

[2] R. H. Hayes and D. M. Upton, "Operations-Based Strategy," California Management Review, vol. 40, no. 4, pp. 8-25, SUM 1998.

[3] K. Hutt and A. Davidson, "Strategies for managing mature products," Strategy \& Leadership, vol. 33, no. 4, pp. 51-52, 2005.

[4] L. Goldin, M. Matalon-Beck, and J. Lapid-Maoz, "Reuse of Requirements Reduces Time to Market," in Proc. EEE International Conference on Software Science, Technology, and Engineering (SWSTE), June 2010, pp. 55-60.

[5] C. Jones, "Patterns of large software systems - failure and success," Computer, vol. 28, no. 3, pp. 86-87, Mar 1995.

[6] K. O. Sánchez and J. R. Osollo, "A strategy for Requirements Engineering Based on Knowledge Management," in Proc. the 2013 Mexican International Conference on Computer Science, Oct.-Nov. 2013, pp. 28-35.

[7] M. C. Lin, C. C Want, and T. C. Chen, "A strategy for managing customer-oriented product design," Concurrent Engineering, vol. 14, no. 3, pp. 231-244, September 2006.

[8] S. P. Robbins and M. K. Coulter, Management, $5^{\text {th }}$ ed. Upper Saddle River, NJ: Prentice Hall, 1996, ISBN 0134865561.

[9] M. Mckeown, The Strategy Book: How to Think and Act Strategically to Deliver Outstanding Results. Pearson UK: FT Prentice Hall, 2012.

[10] D. Wynn, C. Eckert, and P. J. Clarkson, "Planning business processes in product development organisations," in Proc. the 15th Conference on Advanced Information Systems Engineering, Workshop Proceedings, Information Systems for a Connected Society, Klagenfurt/Velden, Austria, 16-20 June 2003, pp. 383-388.

[11] J. M. Hobbs and D. F. Heany, "Coupling strategy to operating plans," Harvard Business Review, vol. 55, no. 3, pp. 119-126, May-June 1977.

[12] N. Acur and U. Bititci, "Managing strategy through business processes," Production Planning \& Control, vol. 14, no. 4, pp. 309-326, June 2003.

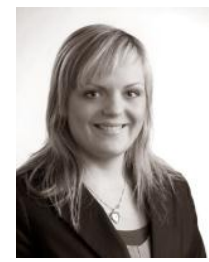

Dagný Hauksdóttir is a Ph.D student at the section of Engineering Design and Product Development at the Technical University of Denmark. The project involves a close industrial cooperation with Danfoss PE where Dagný has worked previously as a process specialist for development projects. Dagný specializes in research topics related to requirements engineering, product architecture and product design and has experience in research in the area of product configuration and mass customization. She can be contacted at dagha@dtu.dk.

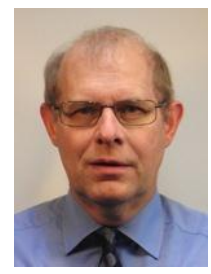

Poul Erik Nielsen is a $R \& D$ process management director in Danfoss' Power Electronics Division in Graasten, Denmark. He holds a M.Sc. in mechanical engineering and a Ph.D. in control engineering from the Technical University of Denmark.

He has a broad experience from industry and has worked with control engineering, project and program management, product platform management and processes for lean pr oduct development, including RM processes. He can be contacted at: poul_erik_nielsen@danfoss.com 